\title{
RESEARCH ON THE DEVELOPMENT OF HIGHER VOCATIONAL EDUCATION POLICY IN CHINA
}

\author{
Wang $\mathrm{B}^{*}$ and Gedviliene G \\ Education Academy, Vytautas Magnus University, Lithuania
}

\begin{abstract}
Higher vocational education is an important part of higher education in China. With the rapid development of China economy, social demands for more high-quality talents than ever before. There are many factors affecting the development of higher vocational education, especially policy. The state has issued a series of policies on promoting the development of higher vocational education. This paper uses the literature method and the comparative research method. By consulting the relevant literature and materials, we will analyze and summarize the characteristics and direction of the Chinese higher vocational education policy in the past ten years, and summarize the highlights of the higher vocational education policy in developed countries. Through comparative research method, China's higher vocational education policy is divided into six categories: 1. Policies on the reform of school system and mechanism; 2. Policies on accelerating the construction of a modern vocational education system; 3 . Policies on improving the quality of talent training in vocational colleges; 4. Policies on deepening the integration of industry and education; 5. Policies on strengthening the construction of teachers; 6 . Improving the development of vocational education policy on the levels of barriers. This paper is divided into three parts. The first part discusses the background and research status of this research topic. The second part analyzes the stage characteristics of the development of Higher Vocational Education in China by selecting and analyzing the policies on Higher Vocational Education issued by the state since 2010-2020. The third part summarizes and analyzes the trend of China's higher vocational education policymaking in the future.
\end{abstract}

Keywords: China's higher vocational education, policy development

\section{Introduction}

\section{The Study Background}

China's higher vocational education has undergone a series of reforms and vicissitudes from existence to non-existence. Entering into the $21^{\text {st }}$ century, the rapid development of economy has prompted the society to demand a huge number of higher vocational talents.

According to statistics, in 2010, higher vocational school students reached 9.662 million (Jiping, 2016). In 2014, the number of students in China's higher vocational colleges was 10.66 million, exceeding the 10 million mark for the first time, accounting for 40 percent of the total scale of higher education. In 2018, there were 2,663 regular colleges and universities (including 265 independent colleges) and 1,418 vocational colleges, with an annual enrollment of 3.6883 million and 11.337 million students.(Yuting, 2018) From 2015 to 2019, the number of vocational colleges increased by 
82 , and the number of undergraduate vocational colleges increased by 15 ; The number of students in vocational colleges increased by 2.321 million, and vocational schools at the undergraduate level began to enroll students.( CED,2021) By 2020, there will be 1,468 vocational colleges.( DDP, ME, PRC,2021)

As can be seen from the data, higher vocational education, as an important part of China's vocational education, has seen its status rising year by year. Whether higher vocational education can develop healthily and stably is affected by many factors. Among them, the policy factor played a decisive role.

The cultivation of high quality and high skill creative talents depends on the development of vocational education, especially higher vocational education. At present, there are many deficiencies in the development of higher vocational education in our country, and the continuous improvement of relevant policies is conducive to the steady development of higher vocational education. The research on higher vocational education policy can help us to have a clear understanding of the problems and deficiencies existing in policy formulation and the development of higher vocational education, which is helpful for us to find and solve problems and promote the perfection and development of higher vocational education policy in China. Policy has timeliness, in each stage of historical development; it needs to make corresponding adjustment and improvement according to its actual situation.

\section{Relevant Literature}

In recent years, with the continuous development of vocational education, especially higher vocational education, scholars have gradually increased their research on relevant policies. By searching the authoritative website of Chinese academic journals "CNKI", we can find that there are 2545 papers on the topic of "vocational education policy", among which there are 798 dissertations of master and doctoral degree. There are 219 literatures and 19 dissertations on the subject of "Higher Vocational Education Policy". Thus, although there is more interest in higher vocational education policies than before, the study population is still limited. In the research field of higher vocational education, there are few researches on higher vocational education policy. The research on its policy mainly focuses on the text analysis and development stage division of higher vocational education policy, the problems and countermeasures of higher vocational education policy, the development trend and future trend of higher vocational education, the comparison of Chinese and foreign higher vocational education policy and various policies of higher vocational education.

According to the characteristics of different stages of policy formulation of higher vocational education in China, different scholars divided the policy development into different stages. Li Gaihu and Yang Guilan divided the development course of China's higher vocational education policy into five stages. (Gaihu and Guilan, 2010) Wang Yingmi and Zhang Leping took the reform and opening up as the time point and divided the evolution of China's higher vocational education policy into four stages: "The first stage (1982-1990): clarifying direction and establishing a typological structure; The second stage (1991-1997): constructing higher vocational education system and promoting the second stage of structural reform; The third stage (1998-2005) : improving the quality of training; the fourth stage (2006-now): highlighting the characteristics of development. Four points of thinking are put forward to perfect the policy of higher vocational education in China." (Yingmi and Leping, 2013) Chen Youli believes that: "China's higher vocational education policy development should be divided into four stages: the first stage is the stage of higher vocational education status gradually established 
(1978-1998); the second stage is the scale expansion stage of higher vocational education (19992004); the third stage is the connotation development stage of higher vocational education (20052013); the fourth stage is the stage of making higher vocational education better and stronger (2014present)." (Youli, 2018) Zhang Hongyun believes that: "the development of higher vocational education policy in China can be divided into three stages: the first stage is the initial stage of higher vocational education in the new century (2000-2004), the second stage is the large development stage of the quantity and scale of higher vocational education (2005-2009), and the third stage is the stage of quality improvement and connotation development (2010-now)." (Zhang Hongyun, 2014) Wu Yiming divided: "the development of China's higher vocational education policy into the establishment stage (1996-1999), the scale expansion stage (2000-2005), the development transformation stage (2006-2014) and the connotation construction stage (2014-present)." (Yiming, 2015)

Different scholars have chosen different emphases to analyze the phased characteristics of China's higher education policies, so the results of the final division are also different. This paper will discuss and analyze the decade from 2010 to 2020 as a stage.

In this paper, author will also conclude the experience and enlightenment from other country, take the vocational education policies of German and Australia as examples, and analyze the weak points of the current vocational education policies in China.

\section{Research Problem and the Research Objectives}

\section{Research Problem}

1. What are the development trends of higher vocational education policy in China?

2. What is the direction of future policy making?

3. How to formulate the higher vocational education policy in China more scientifically?

\section{Research Objectives}

By reviewing the development course of China's higher vocational education policy, in recent ten years (2010-2020) years, China's higher vocational education policy formulation, analysis of the development trend of China's higher vocational education policy, and learn to experience excellent set of higher vocational education policy in developed countries, put forward the scientific Suggestions to formulate the policy of China's higher vocational education.

\section{Research Contents and Methods}

The research topic of this paper is the policy development of higher vocational education in China (2010-2020). The main research methods to be adopted include literature research and comparative research. 


\section{Literature Research}

This paper will analyse and summarize the characteristics and direction of China's higher vocational education policies in the past ten years, and summarize the highlights of the higher vocational education policies in developed countries by consulting relevant literatures.

\section{Comparative Study}

This paper will divide China's higher vocational education policies into the following categories: 1 . Policies on the reform of the school system and mechanism; 2.Policies on accelerating the construction of a modern vocational education system; 3 . Policies on improving the quality of talent training in vocational colleges; 4 . Policies on deepening the integration of industry and education and school-enterprise cooperation; 5. Policies on strengthening the construction of teachers; 6 . Policies to improve the guarantee level for the development of vocational education. And the emphases and implementation forms of these policies are contrastively analysed.

\section{The Analyse of the Policies of Higher Vocational Education in China since 2010-2020}

Since the new century, China has made great efforts to develop higher vocational education. By 2010, there were 22.385 million students in secondary vocational schools and 9.662 million in higher vocational schools. (Jiping, 2016.13-19.) 2010 is a key year for China's higher vocational education. This year, the state issued the Outline of the National Medium-and Long-Term Education Reform and Development Plan (2010-2020). The plan calls for 13.9 million students enrolled in higher vocational education by 2015 and 14.8 million by 2020 . In chapter 6 of the outline, the vocational education sets out in detail the country's requirements for the development of vocational education over the next decade: "By 2020, a modern vocational education system that adapts to the transformation of the economic development pattern and the adjustment of the industrial structure, embodies the concept of lifelong education and the coordinated development of secondary and higher vocational education, meets the people's needs for acceptance of vocational education, and meets the needs of the economy and society for high-quality workers and skilled personnel." (ONMLTRDP (2010-2020), 2010)

Tang Jie and Shi Weiping summarized and analyzed 125 higher vocational education policy texts from 2005 to 2019. According to the number of documents issued by them in the statistical year, the average number of policy texts on Higher Vocational Education issued every year during 2005-2009 was 5, but since 2010, the number of policies on higher vocational education has increased sharply. Among them, more than 10 policies were issued in 2010, 2011, 2017, 2018, 2019. (Jieshi Ping, 2020)

Since 2010, the state has issued vocational education related policies: In 2021, the outline of the $12^{\text {th }}$ Five Year Plan for National Economic and Social Development was adopted by the National People's Congress; Report of the $18^{\text {th }}$ CPC Congress was issued. In 2013, Decision of the CPC Central Committee on Major Issues of Comprehensively Deepening Reform adopted at the Third Plenary Session of the $18^{\text {th }}$ CPC Central Committee. In 2014, General Secretary Xi Jinping issued an important directive on the work of the vocational education, promulgating the Decision of the State Council on Accelerating the Development of the Vocational Education; In 2015, it published the Report of the Standing Committee of the National People's Congress on the Inspection of the Implementation of the Law on Vocational Education, and the Fifth Plenary Session of the $18^{\text {th }}$ Central Committee of the Communist Party of China deliberated and adopted the Proposal of the Central 
Committee of the Communist Party of China for the Formulation of the $13^{\text {th }}$ Five Year Plan for National Economic and Social Development. In 2016, the National People's Congress deliberated and adopted the Outline of the $13^{\text {th }}$ Five-year Plan for National Economic and Social Development. In 2017, the Ministry of Education issued the Notice of Vice Premier Liu Yandong's Speech at the Symposium on Promoting the Modernization of Vocational Education. In 2018, the Ministry of Education and other six departments issued the Circular on Measures to Promote cooperation between vocational schools and enterprises. In 2019, the Ministry of Education issued the Circular on in-depth Study and Implementation of the National Reform and Implementation Plan for Vocational Education; the General Office of the Ministry of Education issued the Circular on the Implementation of the Action Plan for the Innovative Development of Higher Vocational Education (2015-2018); Circular of the Ministry of Education and other four departments issued Printing and Distributing the Implementation Plan for Deepening the Construction of "Double-Qualified" Teachers in Vocational Education in the New Era; the Ministry of Education and the Ministry of Finance issued Opinions on the Implementation of the Plan for the Construction of High Level Vocational Schools and Specialties with Chinese Characteristics; and nine departments including the Ministry of Education issued the Vocational Education Action Plan (2020 -- 2023); the Ministry of Education and the Ministry of Finance issued the Interim Measures for the Performance Management of High-level Vocational Schools and Specialty Construction Plans with Chinese Characteristics. Among them, 59 entries of "Vocational Education" and 31 entries of "higher education" appear in the outline of the national medium and long term education reform and development plan (2010-2020), and 6 entries of "higher vocational education" appear alone. Involving enrolment scale, construction objectives and other aspects, it highlights the important position of Higher Vocational Education in China's educational development.

The promulgation of these major policies points out the direction for the development of higher vocational education. In order to better carry out higher vocational education, the state and local governments at all levels have also issued supplementary policy documents, relevant guidelines and so on. These documents mainly include 6 categories: 1. Policies on the reform of school-running system and mechanism; 2. Policies on accelerating the construction of Modern Vocational Education System; 3. Policies of improving the quality of Personnel Training in vocational colleges; 4. Polices on deepening integration of production, education and school-enterprise cooperation; 5. Policies on strengthening the construction of the teaching staff; 6 . Policies on improving the guarantee level of the development of vocational education. These different policies have different priorities and their effectiveness varies.

After the promulgation of major policies, the state has fully mobilized the efforts of all departments at all levels. All parts and levels of the government have issued supporting documents, detailed implementation of the content, especially the provinces, autonomous regions, in view of the actual situation in the region, issued a series of documents to promote the development of higher vocational education. Under the policy implementation, the National Vocational Education System Mechanism reform gradually appears the effect. The report shows that in 2017, the national financial expenditure on vocational education reached 335 billion yuan; in 2018, the investment in the quality improvement plan for modern vocational education reached 18.7 billion yuan, an increase of 64 per cent over 2014. (CIIN, 2019) According to statistics from the Ministry of Education, in 2019, there were 11,500 vocational schools nationwide, with 28,571,800 students, and 4,836,100 students enrolled in higher 
vocational colleges, accounting for 52.90 per cent of the total, A total of 54.52 million college graduates have been trained, and about 320 million people have been trained in community education. At present, vocational schools across the country have more than 1,200 specialties and more than 100,000 specialty spots, basically covering all fields of the national economy, and training about 10 million high-quality technical and technical talents every year. In such fields as modern manufacturing and strategic emerging industries, more than 70 per cent of the first-line new employees come from graduates of vocational schools. The cooperation between East and West Vocational schools covers the entire area, the cooperation between East and West in recruiting students for secondary vocational schools covers the bottom line, and the vocational schools are fully involved in the three major actions of the cooperation between East and West in Labour services. Over 1.8 billion yuan has been invested in supporting capital and equipment, and a total of 683 professional sites and 338 training bases have been built, more than 160,000 people have been trained in job skills upgrading and more than 23,000 in entrepreneurship training. It is understood that the vocational education has cooperated with the National Development and Reform Commission to cultivate more than 800 enterprises with integration of industry and education, to pilot build 21 cities with integration of industry and education, to set up 1,500 vocational education groups, and to involve more than 30,000 enterprises in the vocational education, steering Committees for Vocational Education and teaching in 56 industries have been set up, and more than 2,200 modern apprenticeship pilot enterprises have been involved. It has established stable ties with more than 70 countries and international organizations, and more than 400 higher vocational colleges have cooperated with foreign educational institutions to run schools, creating an international brand of vocational education in China. (CYD, 2021)

\section{Characteristics of China's vocational education policy from 2010 to 2020}

China has also had a lot of experience in the policy-making of higher vocational education. The policy-making model has gradually been on the right track and has stepped into the road of building higher vocational education with socialist characteristics.

Zhu Zhipeng et al. take the administrative regulations of vocational education as the research object and construct a two-dimensional analysis framework from the two dimensions of basic policy tools and vocational education development, through content coding, tool classification and statistical analysis and other steps to analyze China's vocational education policy. Finally, they summarized the characteristics of China's higher vocational education policy through analysis, that is: "from the perspective of vocational education policy tools, policy tools use has a clear tendency. In the policy texts analyzed, the government is more inclined to use the environmental policy tools to develop the vocational education, in which the strategic measures occupy the absolute superiority, the supply policy tools and the demand policy tools are less frequently used.” (Zhu Zhipeng, et al., 2021)

Wang Yufei and Qi Zhanyong argue that, from a horizontal perspective, the Vocational Education pays attention to the interaction between schools, governments, industries, enterprises and other social forces, and to the formation and function of the external ecological environment of occupation and education, in the constraints of balance, interest game, win-win cooperation in the formation of spiral development; the magnitude of connotative development on a vertical perspective, attention to the scale of vocational education development, structure, management, value orientation, and so on, continue to enhance. (Yufei and Zhanyong, 2020) 
Chen Yue, a scholar concerned about local policy making, proposed that: "the new vocational education policy at the provincial level is closer to the concrete practice of vocational education, the characteristics of power transfer, border transfer and authority reconstruction are more obvious. The first is to form a multi-central governance bodies together constitute the main policy network. The second is to realize that the object of the internationalization policy of vocational education is "the members of the society", that is, the teachers and students of vocational schools, rather than other additional "social problems dealt with by the policy". Third, the integration of global, national and local policy content at three levels, to achieve international standards framework, central macro, policy and local innovation policy seamless interface, positive interaction. Fourthly, beyond the boundaries of the nation-state and the classification of policy tools in the discipline of public administration, relying on political, diplomatic, international law, market and other means, and making comprehensive use of various resources such as authority, information, finance and organization, strengthening non-authoritative policy tools and constructing compound policy toolbox. The fifth is to change the national interest-oriented policy evaluation, and to implement the evaluation system based on public interest, common value, vocational school-based, student-centered vocational education." (Yue, 2020)

After studying the teacher policy of China's higher vocational education since the new century, Kong Qiaoli summarized the policy characteristics: (I) development mechanism: the atmosphere of respecting teachers and valuing education is more prominent; (II) evaluation system: more perfect; (III) International Participation Ability: the internationalization level needs to be deepened; (IV) information literacy: the informatization level needs to be improved (Qiaoli, 2019)

By summarizing the research achievements of other researchers, we can find that the general tone of China's higher vocational education policy-making since $2010-2010$ is to show an attitude towards the status of higher vocational education, that is, higher vocational education, as an important part of higher education, is constantly standardized. The focus of policy-making is: the policy has both international and local characteristics, and is constantly explored A development model suitable for China's national conditions; the integration of industry and education has been strengthened, emphasizing the balance of local development; the construction of high-quality teachers has been highlighted, and more investment has been made in infrastructure construction and teacher training.

\section{The future trend of China's Higher Vocational Education Policy}

Under the international background of increasing demand for high-quality talents, China's higher vocational education has also entered a new period. In the future, China's higher vocational education policy needs to keep up with China's economic development and social needs, and should highlight the advantages of China's large population and form a higher vocational education policy with Chinese characteristics.

In Mo Yuwan's opinion, the focus of China's Higher Vocational Education in the future lies in "innovation", which is mainly reflected in: (1) strengthening classified guidance, paying attention to the innovation of policies and mechanisms, and exploring new models for the development of higher vocational education; (2) standardizing the construction of professional groups, paying attention to the coordination between professional groups and majors, and exploring new paths for professional 
development; (3) expanding the scope of enterprise participation and paying attention to safeguarding the interests of enterprises, Enhance the initiative and depth of enterprise participation. (Yuwan, 2021)

Wang Yingmi and Zhang Leping believe that China's future higher vocational education policy should turn to strategic planning. The state should mainly formulate relevant laws and regulations, use the market and participation mechanism to guide the benign development of Higher Vocational Education from the macro level, and further standardize the aspects where the law is not enough or difficult to exert force, combined with the use of macro policies. (Yingmi\& Leping, 2013)

After analyzing the policy trend of China's Vocational Education in the past 20 years, Ge Daokai put forward the focus of future policy-making: (1) we should put vocational education in a more prominent strategic position and promote the synchronous development of vocational education and economy and society; (2) we should undertake a more arduous mission of the times and take the construction of modern vocational education system as the main direction (3) We should give full play to the important role of enterprises as the main body of running schools, and take deepening the integration of industry and education and school enterprise cooperation as key measures. (4) We should gather the joint force of the whole society to care for and support vocational education, and take promoting the breakthrough of system and mechanism as a strong driving force. (5) We should adhere to the school running direction of serving development and promoting employment, and take improving the training quality of technical and skilled talents as the core task (6) We should strengthen policy support and regulatory guarantee, and take the implementation of government responsibility as an important focus (Daokai, 2015)

Hou Xinxin puts forward several directions from the value choice of future higher vocational education policy-making: (1) pay attention to the needs of multiple subjects and the integration of social standard and personal standard; (2) enhance the effect of policy implementation and balance the value conflict; (3) strengthen the guidance of policy practice and highlight the value of policy (Xinxin, 2020)

Guo Fuchun and Wang Yulong should adhere to the following three points when formulating policies related to the supply side structural reform of Higher Vocational Education: first, promote the coordinated development of schools and enterprises. Second, promote the coordinated development of industry and education. Most of the traditional higher vocational teaching is the combination of theoretical learning and practical operation, focusing on consolidating knowledge and skills. Third, support the cooperation and innovation of teachers and students. (Fuchun, Yulong, 2019)

Based on the research results of many scholars, combined with the current situation and characteristics of China's higher vocational education policy-making, the author believes that several key cores of higher vocational education policy-making in the future are: 1. Pursue efficiency and ensure fairness. Before making policies, we should do a good job in investigating relevant personnel at different levels and find the weaknesses in policy-making. When making policies, We should take into account the demands of different stakeholders. We should try to formulate policies scientifically instead of repeatedly formulating policies with the same dimensions and inconsistent with the reality of current and future development. 2. Scientific management and rational division of labor. When formulating policies, we should fully mobilize the enthusiasm of all departments at all levels and make full use of resources. For example, in terms of investment in higher education, we need the 
cooperation of central finance and local finance with support. After the central government has issued relevant policies, local governments should promote them at the same time, formulate documents in line with the local economic development level and financial situation according to local conditions, and ensure the implementation of the central policies. 3. Integration of industry and education and pay attention to quality. In formulating policies, we need to continue to pay attention to integration of industry and education. Policy formulation should be conducive to mobilizing the enthusiasm of enterprises to participate in Higher Vocational Education and give relevant support At the same time, we should constantly improve various standards, standardize cooperation methods and contents, and have evaluation standards for talents trained by higher vocational education to keep pace with the times.

\section{Conclusion}

Higher Vocational Education, as the most closely related type of education to the development of social economy, is the main way to realize the popularization of higher education in China and the key to affect the popularization of higher education. The development of higher vocational education can not be separated from the support of the government. Looking at the development course of higher vocational education policy in our country, we can find that under the guidance of the policy, higher vocational education in our country has made further development.

As the most developed countries in the vocational education, the governments of Germany, Australia, the US and other countries attach great importance to the investment and policy support for higher vocational education, and the policy formulation is very rigorous. Learning from the experience of other countries, we can make our higher vocational education policy reform achieve better results.

In a word, with the improvement of social modernization level, the society puts forward higher requirements for the quality of higher vocational education, and the national policy support is the guarantee to improve the quality of higher vocational education. In order to meet the new requirements of social and economic development for higher vocational education, the state must constantly adjust the policy of higher vocational education.

Each manuscript should contain a conclusion section which may contain the major outcome of the work, highlighting its importance, limitation, relevance, application and recommendation. Do not use any subheading, citation, references to other part of the manuscript, or point list within the conclusion.

\section{References}

2020 Annual Report on the Quality of Vocational Education in China Shows that the Reform of Vocational Education has Achieved Remarkable Results and Steadily Increased Its Appeal. (2021, May 25). Retrieved from

http://www.moe.gov.cn/jyb_xwfb/xw_zt/moe_357/2021/2021_zt10/zjsy/202105/t20210525_533422. $\mathrm{html}$

Chan Youli. (2018). History, Structure and Impetus of China s Higher Vocational Education Policy in the Past 40 Years of Reform and Opening-up. Academic Education Monthly, (12) : 12-19. 
China's Vocational Education Industry Will Enter a Golden Period with Huge Development Scale, and There Will be Three Obvious Trend Analysis in the Future in 2019. (2019, August 19). Retrieved from

http://www.chyxx.com/industry/201908/773153.html

Chen Yue. (2019). Inter-provincial Comparison of the International Influence of Higher Vocational Education: Policy Implications — on the Quality of Higher Vocational Education in 31 Provinces (2019). Chinese Vocational and Technical Education, (33) : 67-73

Department of Social Development, National Development and Shanghai Reform Commission Institute of Education Sciences. (2015). Study on the development strategy and institutional innovation of vocational education. Shanghai, China: China Planning Press.

Ge Daokai. (2015). 20-year Policy Trend of China's Vocational Education. Curriculum, Teaching Material and Method.

Guo Fuchun, \&Wang Yulong. (2019). Scale, Structure, Quality and Policy: Four Dimensional Analysis of Supply Side Structural Reform of Higher Vocational Education. Heilongjiang Studies on Higher Education.

Hou Xinxin. (2020) Value Analysis of China's Higher Vocational Education Policy -- Exploratory Research based on Grounded Theory. Higher Vocational Education Exploration.

Huang Zhichun. (2010). Characteristics, Experience and Enlightenment of Swiss Higher Vocational Education. Jiangsu Higher Education, (2), 147-148

Jiang Hui. (2002). Introduction to the State and Other Vocational and Technical Education. Lanzhuo, China: Lanzhou People's College Press.

Kong Qiaoli. (2019). Evolution, Characteristics and Trend of China's Higher Vocational Education Teacher Policy in the New Century. Xinjiang Vocational Education Research.

Li Gaihu, \& Guilan. (2010). Analysis of the historical process of China's higher vocational education policy in the past 30 years of reform and opening-up. Journal of the Hunan Industry Polytechnic, (2) : 93-97

Main Results of 2020 National Education Statistics-Ministry of Education of the People's Republic of China. (2021, March, 1). Retrieved from

http://www.moe.gov.cn/jyb_xwfb/gzdt_gzdt/s5987/202103/t20210301_516062.html

Ma Longhai, \& Tian Hongyu. (2004) Reform of Vocational Education in Finland and Its Enlightenment. Modern Intelligence, (4), 186-188

Mo Yuwan. (2021). Key Construction of Higher Vocational Education in China: Policy Change, Path Dependence and Reform Trend. Higher Education Exploration.

Outline of the National Plan for Medium and Long-term Education Reform and Development (20102020). (2010, July 29). Retrieved from

http://www.moe.gov.cn/srcsite/A01/s7048/201007/t20100729_171904.html

Pan Maoyuan, \& Zhu Leping. (2019). the Logic of Policy Change in Higher Vocational Education: a Historical Institutional Perspective. Education Research

Su Cuiping. (2011). Policy Research on Higher Vocational Education. Shandong, China: Shandong University.

Tang Jieshi, \& WeiPing. (2020). Policy Tools for Connotation Construction of Higher Vocational Education: Review and Prospect -- Based on the Analysis of Higher Vocational Policy Texts from 1995 to 2019. Education Research Monthly. 
Tao Qiuyan. (2004). Higher Technical Vocational Education. Beijing, China: Science Press.

Wang Binhua. (1996). Australian Education. Shanghai, China: Huangdong Normal University Press.

Wang Jiping. (2016). Department of Education Reform of China (Vocational Education). Wuhan, China, Hubei Education Press.

Wang Yufei, \& Qi Zhanyong. (2020). Analysis of the Elements of Vocational Education Reform in China - Analysis Based on the Text of Vocational Education Policy. Education Research Monthly, (11) : 28-36)

Wang Yingmi, \& Zhang Leping. (2013). Text Analysis of China's Education Policy since the Reform and Opening-up. Vocational and Technical Education, (13)5-9

World's Largest Academic Breakthrough "Ceiling" Training Tens of Millions of Skilled Personnel Each Year. (2021, January 26). Retrieved from

http://www.moe.gov.cn/jyb_xwfb/xw_zt/moe_357/2021/2021_zt04/fz/202101/t20210126_511093.ht $\mathrm{ml}$

Wu Yan. (2005). Comparative Study on the Policy Orientation of the American Federal Government in Higher Vocational Education. Education Research, (9), 70-75

Wu Yiming. (2015). Policy Evolution, impetus and adjustment of higher vocational education in China. Education Development Research, (19) : 7-9.

Ye Yuting. (2018, July 16). For the first time in 10 years, the Employment Rate of Higher Vocational Graduates exceeds that of Undergraduates. China Youth Daily

Zhang Hongyun. (2014). A Study on the Policy Development of Higher Vocational Education in China at the Beginning of the 21st Century. Tianjin, China: Tianjin University

Zhu Zhipeng, Zhang Jiawei \& Yang Haihua. (2021). Analysis of China's Vocational Education Policy from the Perspective of Policy Tool — based on the National Administrative Regulations on Vocational Education since 2002. Vocational Education Newsletter, (2) : 49-67 